\title{
Low Cost, Compact, and High Efficiency Traction Motor for Electric and Hybrid Electric Vehicles
}

\section{Project Overview}

A suitable motor drive for vehicle traction should offer high efficiency, compactness, and low cost of manufacturing, among other attributes. Recently, we have discovered that vehicle dynamics such as initial acceleration and gradeability demands an extended constant power region in the motor torque speed plane. This, in turn, can be interpreted as a novel method to reduce the power rating of the motor drive, thereby producing a more compact drive train for EV and HEV. In addition, it is important to remember that a successful motor drive must provide a fault tolerant and hazard free operation. Switched Reluctance Motor (SRM) drives, once properly designed and controlled, are capable of providing all of the vehicle requirements while demonstrating a low cost, reliable, compact and highly efficient performance.

In this project, our team at Texas A\&M University has designed and developed a bench scale SRM drive, specifically suited for EV and HEV applications. In addition, we have introduced a specific control strategy to obtain an extended constant power region by tuning the control parameters. Furthermore, we have developed a self-tuning technique that can result in a relaxed manufacturing precision, producing a low cost traction drive. We also have developed a four-quadrant position sensorless controller, which can significantly improve the reliability and overall cost of the drive. The successful integration of these novel technologies will deliver a low cost, highly efficient and compact solution for traction in EV and HEV applications.

\section{Phase I Project Results}

An optimized SRM geometry has been designed. Finite Element (FE) analysis has been used for computation of nonlinear characteristics of the SRM. Figure 1 shows the cross section of the designed machine along with the magnetic flux lines. In order to finalize the design, a dynamic simulation of the SRM has been performed. Nonlinear flux and torque characteristics of the SRM (obtained using FE analysis) have been used for this simulation study (Fig. 2). In the next step, a bench scale prototype of the designed machine $(300 \mathrm{~V}, 7.5 \mathrm{~kW})$ has been developed. Figure 3 shows the stator and rotor of the designed SRM. This machine has been then used in an experimental test bed as shown in Fig. 4. Having completed the various parts of the drive system, such as the inverter, control electronics and software, we are performing the final testing of the proposed drive.

Our results show that SRM drive can be considered a serious candidate for EV and HEV traction applications. Furthermore, integration of self tuning and sensorless techniques in the future phases of this project can produce a prototype for low cost, compact and highly efficient drives for traction applications. DOE Patent Clearance Granted

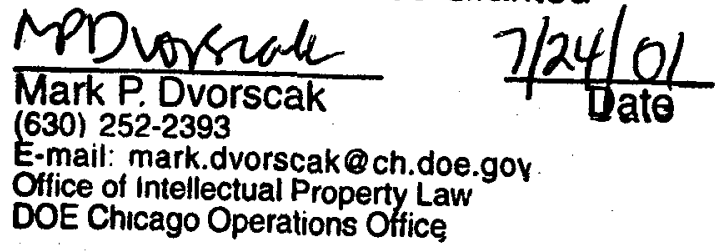




\section{DISCLAIMER}

This report was prepared as an account of work sponsored by an agency of the United States Government. Neither the United States Governmeat nor any agency thereof, nor any of their cmployes, makes any warranty, express or implied, or assumes iny legal liability or responsibitity for the accuracy, completeness, or usefulness of any information, epparatus, product, or process disclosed, or represents that its use would not infringe privately owned rights. Reference herein to any specific commercial product, process, or service by trade aame, trademark, manufacturer, or otherwise does not necessarily constitute or imply its endorsement, recommendation, or favoring by the United States Government or any agency thereof. The views and opinions of authors expressed herein do not necessarily state or reflect those of the United States Governmeat or any ageacy thereof. 


\section{DISCLAIMER}

Portions of this document may be illegible in electronic image products. Images are produced from the best available original document. 


\section{Contact:}

Prof. Mark Ehsani, Ph.D., P.E., F. IEEE.

Director,

Advanced Vehicle Systems Research Program

Texas A\&M University

Department of Electrical Engineering

College Station, TX 77843-3128

Phone: (409) 845-7582

Fax: (409) 862-1976

EML: ehsani@ee.tamu.edu

URL: http://ee.tamu.edu/ ehsani

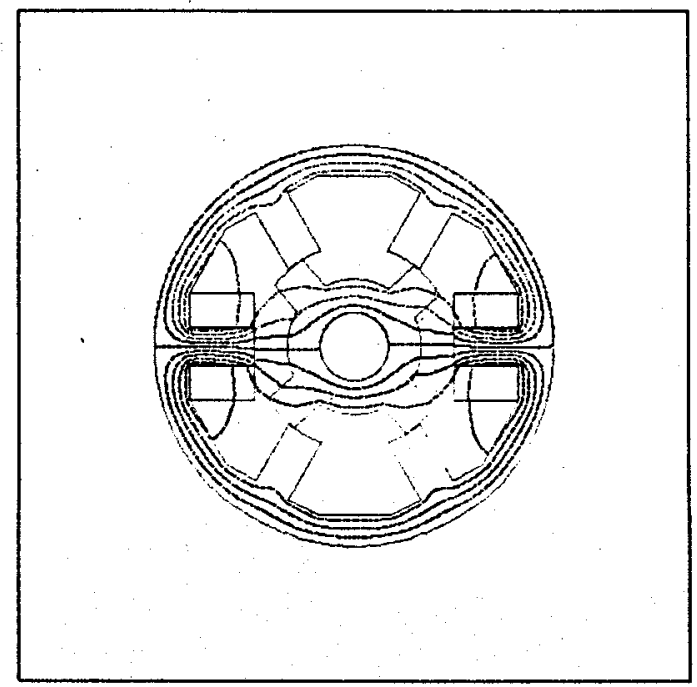

Fig.1, Cross section of the designed SRM along with the magnetic flux lines 


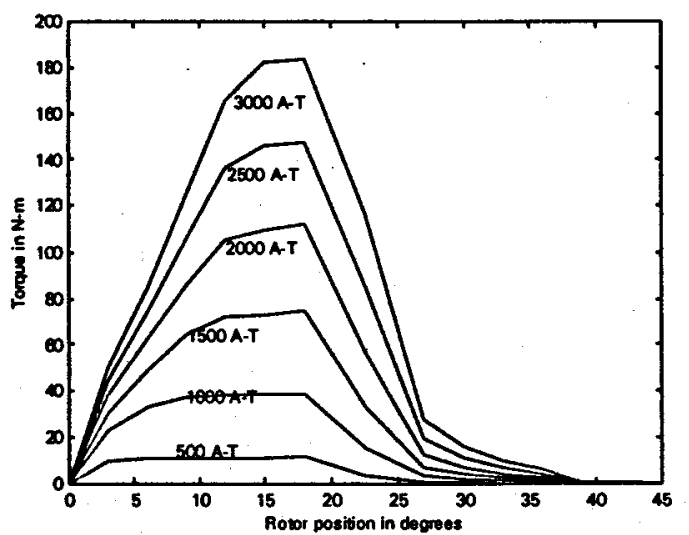

(a) Static torque vs rotor position for different ampere-turns

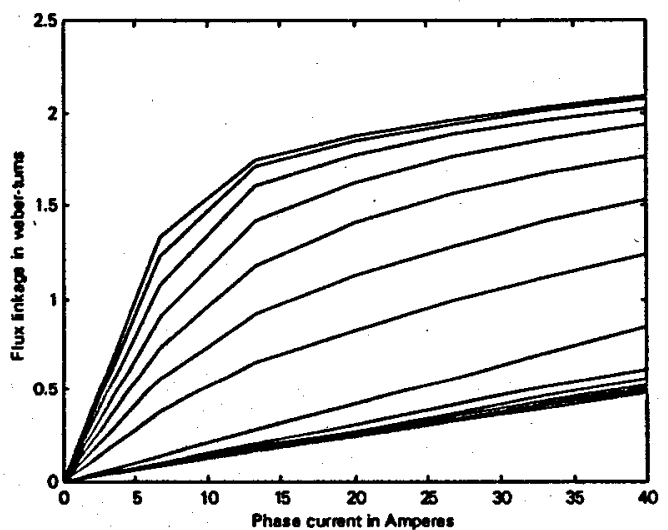

(b) Static flux linkage vs phase current for different rotor positions Fig.2, Magnetic charcteristics of the designed SRM 


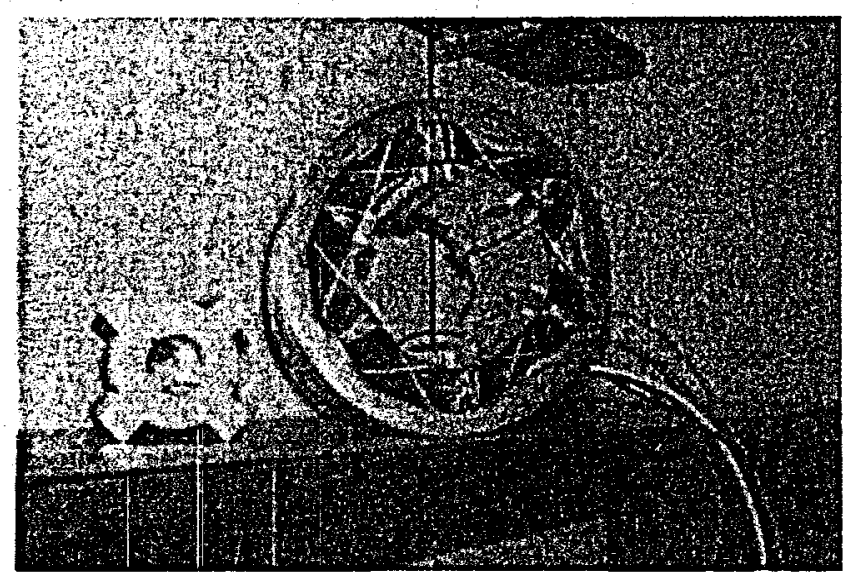

Fig.3, Rotor and Stator of the designed SRM 


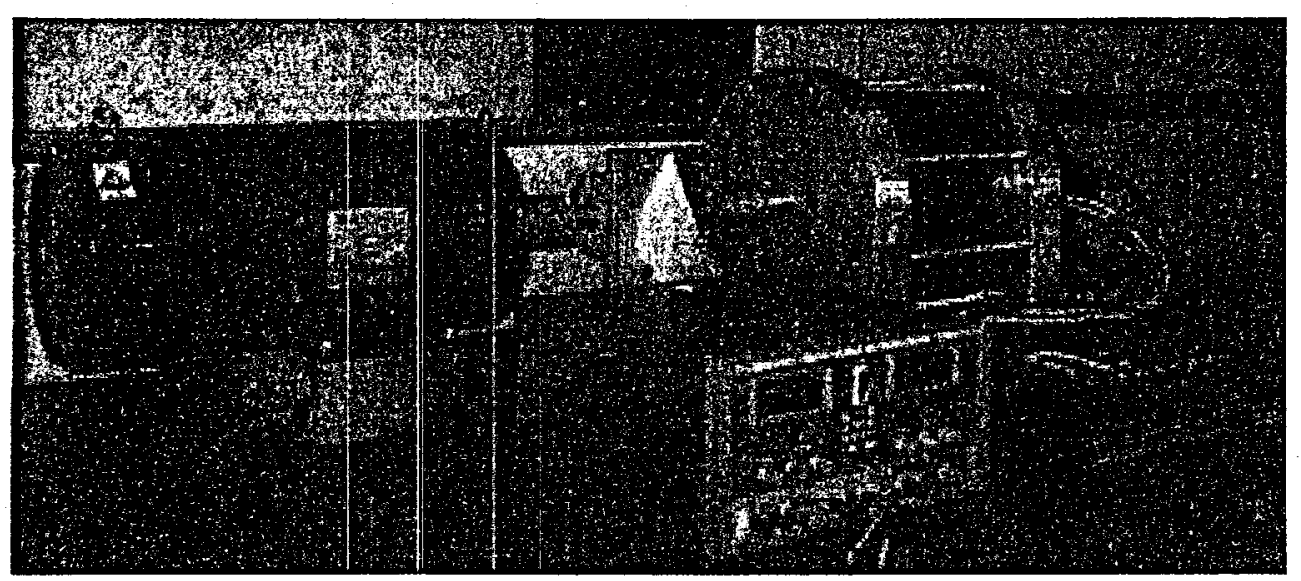

Fig.4, A bench scale SRM drive for EV and HEV investigation 